Radiologe 2021 61 (Suppl 1):S29-S38 https://doi.org/10.1007/s00117-021-00939-8 Accepted: 15 November 2021 Published online: 30 November 2021 (c) The Author(s), under exclusive licence to Springer Medizin Verlag GmbH, ein Teil von Springer Nature 2021

\section{Emergency radiology training in Germany: current status and future directions}

\author{
Stefan Wirth ${ }^{1,2,3} \cdot$ Ferco H. Berger ${ }^{4}$. Ana Blanco Barrio ${ }^{3,5} \cdot$ Martin G. Wagner ${ }^{6}$. \\ Raffaela Basilico ${ }^{3,7}$ \\ 'Institut für Radiologie und Nuklearmedizin, Schwarzwald-Baar-Klinikum, Villingen Schwenningen, \\ Germany \\ ${ }^{2}$ Klinik und Poliklinik für Radiologie, Medizinische Fakultät der LMU München, Klinikum der LMU \\ München, Munich, Germany \\ ${ }^{3}$ European Society of Emergency Radiology, Vienna, Austria \\ ${ }^{4}$ Emergency \& Trauma Radiology Division, Sunnybrook Health Sciences Centre, Department of Medical \\ Imaging, University of Toronto, Toronto, Canada \\ ${ }^{5}$ Servicio de Radiodiagnóstico. Sección de Radiología de Urgencias, Hospital G.U. Morales Meseguer, \\ Murcia, Spain \\ ${ }^{6}$ Klinik für Gefäßchirurgie, Helios Klinikum München West, Munich, Germany \\ ${ }^{7}$ Department of Imaging, SS Annunziata University Hospital—Chieti, Chieti, Italy
}

\title{
Abstract
}

Background: Emergency radiology (ER) is an important part of radiology. But what exactly is ER? How can the required competencies be acquired in a good and feasible way? Who should be in charge of this?

Objectives: Discussion of ER contents and suggestions for the improvement of the acquisition of respective competencies during radiology training.

Materials and methods: General literature review, in particular the current German blueprint for medical specialist training regulations (Weiterbildungsordnung, WBO 2020), publications by the German Radiological Society (DRG), the European Society of Radiology (ESR), the European Society of Emergency Radiology (ESER) and the American Society of Emergency Radiology (ASER).

Results and conclusions: As proof of competence in ER in Germany, confirmation from the authorised residency training supervisor as to whether there is 'competence to act' either 'independently' or 'under supervision' in the case of 'radiology in an emergency situation ..., e.g. in the case of polytrauma, stroke, intensive care patients' is sufficient. The ESER refers to all acute emergencies with clinical constellations requiring an immediate diagnosis 24/7 and, if necessary, acute therapy. The ESER and ASER offer, among other things, practical fellowships in specialised institutions, while the ESER complements this with a European Diploma in Emergency Radiology (EDER). On a national level, it would be advisable to use existing definitions, offers and concepts, from the ESR, ESER and ASER. Specialised institutions could support the acquisition of ER competencies with fellowships. For Germany, it seems sensible to set up a separate working group (Arbeitsgemeinschaft, AG) on ER within the DRG in order to drive the corresponding further ER development.

\section{Keywords}

Acute radiology · Emergency setting · Radiological training · European Diploma in Emergency Radiology · Fellowship · Competencies 


\section{Background}

Emergency radiology (ER) has been an important part of radiology from the outset [1]. Continuous technical innovation resulted in ever more precise and faster procedures, which further increased the value in acute diagnostics as the basis of fast and appropriate therapy [2]. Further improvements in care brought the complete digitalisation of images and reports as well as step-by-step radiological integration into emergency rooms, which are also becoming increasingly interdisciplinary. In addition to immediate on-site computed tomography (CT) diagnostics, radiology is involved in the development of emergency room tracts, in the maximum stage with the option of immediate $\mathrm{CT}$ diagnostics as well as the interventional treatment of acute heart attacks, strokes, bleeding or other vascular occlusions. Large centres even operate $\mathrm{CT}$ directly in the emergency room or use so-called sliding gantry concepts in order to be able to equip a CT from both the emergency room and an adjacent $\mathrm{CT}$ room.

The driving forces behind these developments include the ever better technical possibilities in combination with the proven positive effects of time savings on morbidity and mortality in the early acute/ emergency phase [2]. In addition, there is continuous growth in the number of acute patients [3, 4]. As a consequence, ER comes increasingly into focus. On the other hand, ER also leaves room for an exact definition of the field and, once given that, how the required competencies may be acquired/trained in a good as well as feasible way.

\section{Objectives}

Discussion of ER contents and suggestions for the improvement of the acquisition of respective competencies during radiology training.

\section{Materials and methods}

General literature review, in particular the current German blueprint for medical specialist training regulations (Weiterbildungsordnung, WBO 2020) [5], publications by the German Radiological Society
(Deutsche Röntgengesellschaft, DRG), the European Society for Radiology (ESR), the European Society for Emergency Radiology (ESER) and the American Society for Emergency Radiology (ASER). Parts of the materials, methods and results integrate translations of a thematically appropriate medical doctoral thesis [6] and a respectively related previous publication [7].

\section{Results}

The European Union (EU) has regulated the free movement of goods, people, services and capital, which also includes mutual national recognition of professional qualifications [8]. As far as radiology is concerned, the training times as well as the accessible radiological specialisations differ from country to country, in some cases considerably. In view of these aspects, it seems sensible not only to align the process to the German framework, but also to expand it to an international and, in particular, EU level.

\section{Emergency radiology within the German Radiological Society}

In Germany, ER is part of general radiological training and is therefore not formally a separate radiological specialisation that could be acquired as separate board certification (in Germany this type of official advanced qualification in Radiology as a subspecialisation is only possible in paediatric radiology and neuroradiology and, recently, also as an additional qualification in diagnostic nuclear medicine for radiologists). However, there is a whole range of technical subspecialisations or special expertise within radiology but without medical board certification. Such groups of core expertise are mainly organised by particular subsocieties and the DRG. The DRG groups them in the form of working groups (Arbeitsgemeinschaften, AGs) [9]. These are subdivided differently, sometimes according to modalities (e.g. ultrasound), body regions (e.g. chest), organs (e.g. breast diagnostics), organ systems (e.g. musculoskeletal, MSK), disease groups (e.g. oncological imaging), current research fields (e.g. forensic radiology) and interfaces (e.g. physics).
Currently, there is no separate ER working group within the DRG. Instead, emergencies are spread across various working groups. These do not cover the entire range of radiology and certainly not the entire range of ER. For example, polytrauma is assigned to the AG MSK, which has proposed its own curriculum in which MSK trauma but not polytrauma is covered [10]. On the other hand, the homepage at least refers to its own recommendations for polytrauma whole-body CT protocols [11]. The recommendations rely on the working group 'Imaging procedures of the musculoskeletal system', the direct predecessor of the working group 'MSK', which was recently renamed. Otherwise there is no corresponding reference to ER [12]. In the radiological curriculum developed by the DRG with regard to the national competency-based catalogue of learning objectives for medicine (Nationaler Kompetenzbasierter Lernzielkatalog Medizin, NKLM), some emergencies are also divided into special radiological areas. Particular learning goals for ER are not suggested. For example, the word 'emergency' is only found at one place within the curriculum: "Knowledge of procedures in emergency situations in interventional radiology" [13, p. 16]. D Figure 1 shows an example of why ER competence and expertise are needed to direct correct therapy pathways in sometimes subtle image abnormalities.

Emergency radiology in the German blueprint for medical specialist training regulations (WBO 2020)

The German Medical Association put the new blueprint for medical specialist training regulations (WBO) into effect and last updated them on June 26th, 2021 [5]. The state medical associations have implemented this in the form of respective concrete training regulations, although there are virtually no state-specific differences. The WBO generally states: "In the interests of the patient, the medical competencies and attitudes shaped during study and undergraduate training are deepened during the training as a specialist. The in-depth application of medical knowledge in professional practice is characteristic of specialist training ... in practical work and theoretical instruction as well as partly 

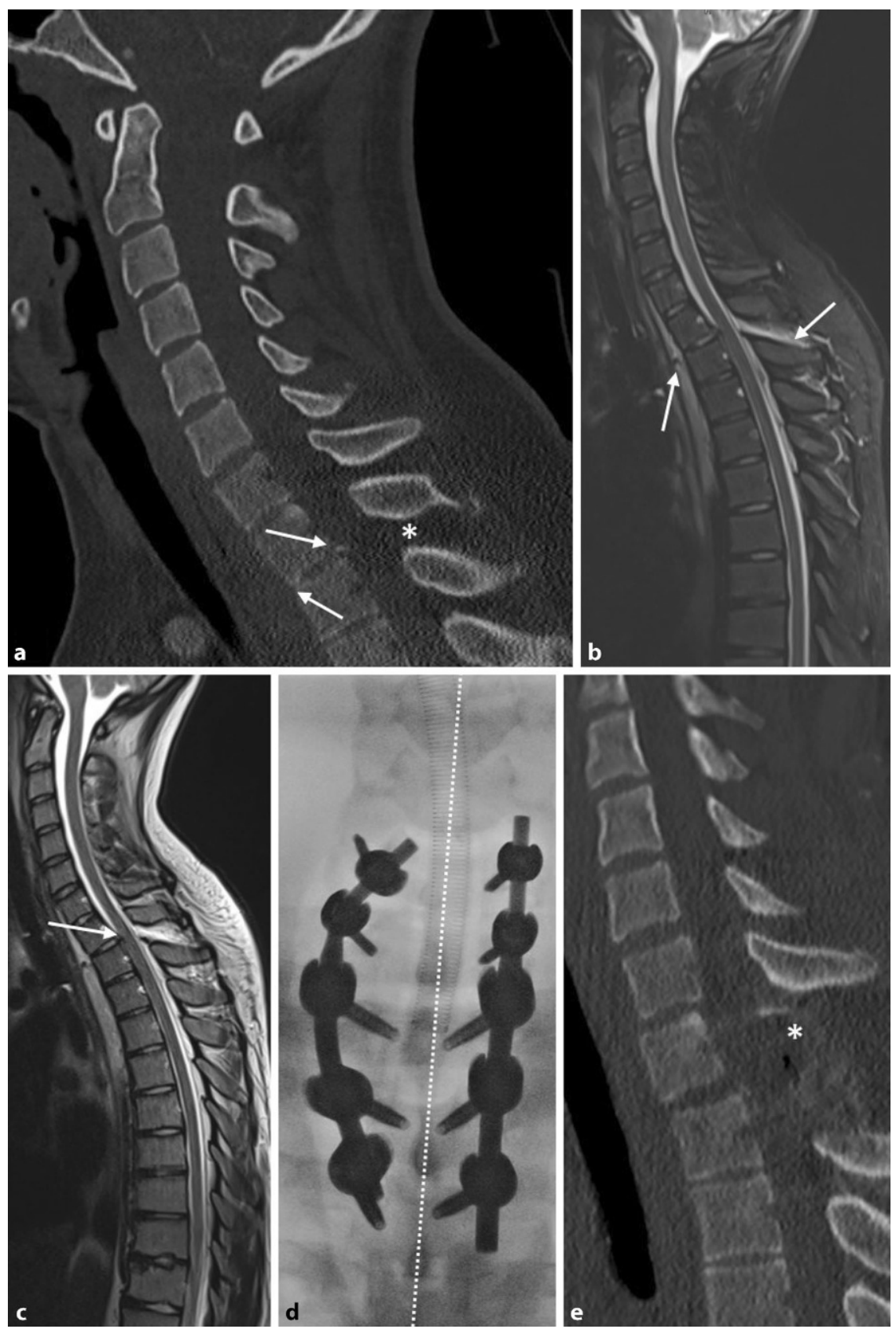

Fig. $1 \Delta$ Unstable injury of the thoracic spine between the first and second vertebra. Polytrauma (car accident, female, 17 years). a Whole-body computed tomography (CT) of the spine (sagittal). Notice the overlying artefacts coming from the shoulder girdle in the lower part of the image. Only subtle changes point to an unstable spine fracture. Ventral narrowing of the relevant intervertebral space (arrow pointing left), soft tissue swelling there directly prevertebral and widening of the corresponding interspinosal distance (asterisk), subtle fragment (arrow pointing right). b Short Tau Inversion Recovery sequence, c (T2-weighted): expertise in emergency radiology directly initiated immediate magnetic resonance imaging showing all three vertebral columns involved (ventral ligament and interspinosal disruption in b, middle column and low-grade medullary edema in c, arrow). d, e The patient directly went to the operating room with laminectomy, postoperative subtle anterolisthetic fixation (asterisk) and fixateur interne stabilisation (d) as well as postoperative $\mathrm{CT}$ (e, screws not visible as reformatted corresponding to the dotted line in d). Paraplegia that had developed then receded before discharge through successful participation in recognized courses. ... A passed examination is proof of the competence acquired" [5, p. 7]. To hold a title as medical specialist, e.g. as a radiologist, requires that criteria of the WBO are met and a specialist examination is passed [5, p. 9]. The WBO criteria are divided into "cognitive and methodological skills (knowledge)" and "practical skills (experience and skills)". A minimum number of examinations is often required for some criteria (reference numbers). If not, confirmation by the trainer, authorised by the respective medical chamber, in the form of a filled checkbox in the electronic logbook belonging to the WBO is sufficient, occasionally with the option of selecting the competence level of the trainee. This includes interventional stroke therapy as a required 'action competence' (- Fig. 2 and 3).

Regarding ER, proof of confidence in the form of checkbox confirmation by the trainer as to whether at the end of radiology training the trainee has reached a competence level for handling "radiology in an emergency situation ..., e.g. with multiple trauma, stroke, intensive care patients" either "independently" or "under supervision" is sufficient in Germany [5, p. 285]. There is no explanation as to what "radiology in an emergency situation" means precisely and there are no explicit requirements for ER knowledge. For reference numbers of performed/reported examinations only general requirements exist. However, these need to be fulfilled without any specific reference to ER [5, p. 285-8]. It is also not required that radiological services outside of normal working hours have been performed. In addition, it is also not mandatory that radiological training has taken place in a hospital.

The specialist examination is organised out by the medical association of the federal state. Of course, ER will often be part of the exam, but this is not a prerequisite. As long as the trainer certifies existing competence in 'radiology in emergency situations' in the logbook at least as 'under supervision', it would be overall conceivable that it may be possible to become a board-certified specialist in Radiology without further training in a hospital, without practical decisionmaking experience in night shifts, without 


\begin{tabular}{|c|l|l|l|l|l|l|}
\hline Emergency Radiology & 0/1** \\
\hline $\begin{array}{c}\text { Cognitive and } \\
\text { methodological } \\
\begin{array}{c}\text { Competence } \\
\text { Expertise }\end{array}\end{array}$ & $\begin{array}{l}\text { Action Competence } \\
\text { Experience and skills }\end{array}$ & $\begin{array}{c}\text { Proven examination } \\
\text { figures/reference } \\
\text { figures }\end{array}$ & $\begin{array}{c}\text { Name and } \\
\text { describe }\end{array}$ & $\begin{array}{c}\text { Classify and } \\
\text { explain } \\
\text { systematically }\end{array}$ & $\begin{array}{c}\text { Perform } \\
\text { under } \\
\text { supervision }\end{array}$ & $\begin{array}{c}\text { Perform } \\
\text { self- } \\
\text { responsibly }\end{array}$ \\
\hline & $\begin{array}{l}\text { Radiological } \\
\text { examinations } \\
\text { including interventions } \\
\text { in patients with acute } \\
\text { life-threatening } \\
\text { conditions, e.g. in } \\
\text { polytrauma, stroke, } \\
\text { intensive care patients }\end{array}$ & & & $\square$ \\
$\square$
\end{tabular}

Fig. $2 \Delta$ Requirements for "Radiology in an emergency situation" in the Radiology logbook according to the German blue print for medical specialist training regulations. Example of the logbook of the Baden-Württemberg State Medical Association for the 2020 German blueprint for medical specialist training regulations. ${ }^{* *}$ Automatic checking whether the requirement is met. In the example, none of the two possible checkbox options in the two right columns is selected. Therefore, the $0 / 1$ requirement is met (WBO 2020, [5])

experience of examinations acquired in patients with acutely life-threatening conditions and without corresponding content in the specialist examination.

\section{Other examples of emergency care} in the German blueprint for medical specialist training regulations (WBO 2020)

Internal Medicine [5, p. $119 \mathrm{ff}]$ : The training includes at least 6 months of work in the emergency room and another 6 months on the intensive care unit. In a general section, competencies are also described without a minimum number of cases (e.g. cardiopulmonary resuscitation, emergency ultrasound, puncture and catheterisation techniques). There are also no specific minimum numbers for emergencies noted in the various specialisations.

Surgery $[5$, p. $45 \mathrm{ff}]$ : As in internal medicine, the training includes at least 6 months of work in the emergency room and another 6 months on the intensive care unit. In a general section, competencies are also described in this regard (e.g. detection and treatment of acute emergencies including life-saving measures, chest drainage system). With the exception of the requirement for 20 central venous accesses, no minimum case numbers are given in the general part either. This changes with the special content. There, for example, case numbers of this kind were required for emergency interventions. For example, "competence to act" requires at least 10 cases of "Detection, diagnostics, therapy and interdisciplinary management for the severely and multiple injured" and 20 cases of "Emergency interventions in the abdominal cavity, e.g. in ileus, bleeding, peritonitis, spleen rupture, hollow organ perforations". This is continued in more detail in the respective further surgical specialisations (such as vascular surgery, orthopaedic surgery, etc.) (- Fig. 4).

\section{Emergency radiology on an international level}

\section{Emergency radiology within the} European Society of Radiology (ESR) With the European Training Curriculum for Subspecialisation in Radiology (ETC Level III, [14]), the ESR proposes the framework for specialisation in radiology in Europe: Level I represents general radiology training, Level II includes some aspects for subspecialisation-but in contrast to Level III, also within the general training period, meaning the time of training before board certification in general radiology. It includes requirements for the duration and structure of the training as well as infrastructural aspects, describes the concept of the roles of the physician according to CanMEDS [15] and the concept of knowledge, skills, competencies and attitudes (KSCA) and contains specific learning objectives for the respective focus specialisations, which are designed together with the corresponding societies for radiological subspecialisation. Although ETC Level III is only a recommendation, the aim was to achieve the highest possible conformity with the content, not only to ensure compliance with European quality standards, but also to ensure ongoing subsociety support from the parent/umbrella society ESR.

The duration of the specialisation is set to be at least 1 year. The focus should be on the acquisition of skills and should be recorded in a logbook together with the number of examinations performed. Any competences that may have been achieved and documented prior to specialisation should be recognised. At the end of the training, a final exam should check whether the learning objectives have been achieved. During the specialist training, independent scientific work and a transition to continuous professional development should be promoted. A reaccreditation should take place every 5 years, whereby a minimum of subject-specific continuing medical education (CME) points and working hours, which are performed in the field of specialisation, should be specified [14, p. $7 \mathrm{f}$.].

The training may be parallel to normal working in cooperation of a suitable specialist department of a large radiological clinic. Superordinate and specific learning objectives should be clearly formulated 

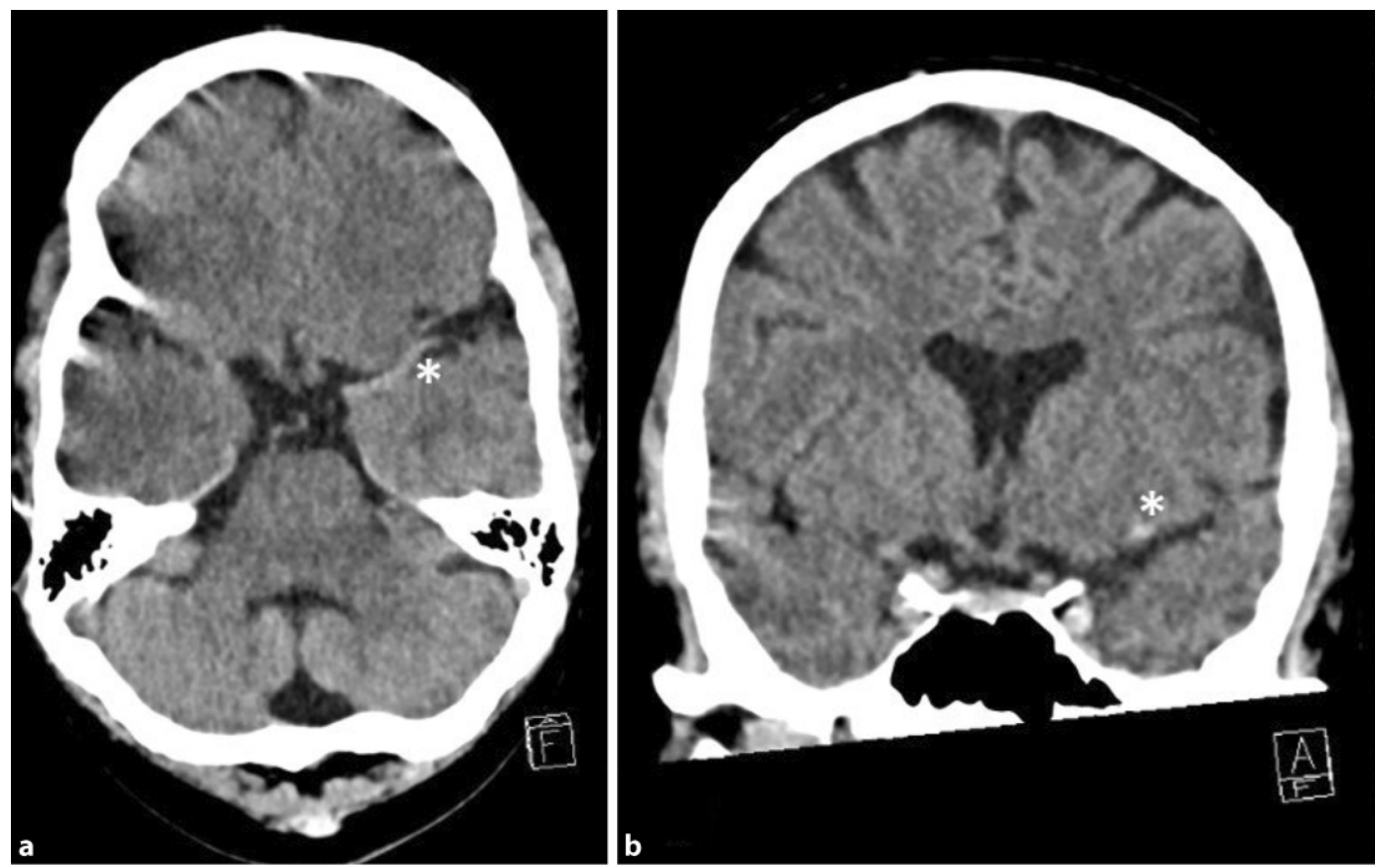

Fig. $3<$ Interventional therapy of two neuroradiological cases. Case 1 (female, 36 years): suc-
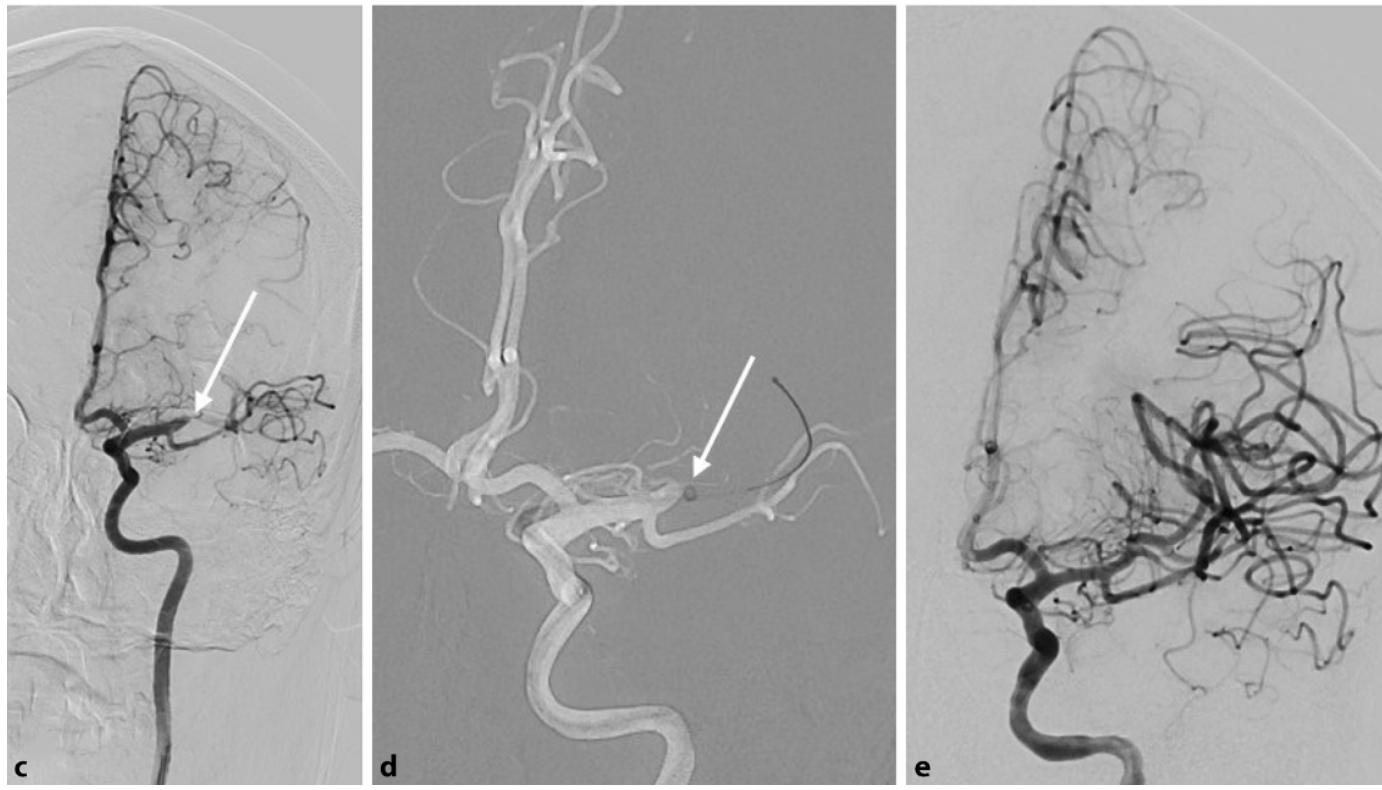
cessful M1 thrombectomy (upper row, a-e); case 2: coil filling of a ruptured posterior communicating artery (PCOM) aneurysm (lower row, $\mathbf{f}-\mathbf{j}$ ). Case 1: unenhanced computed tomography (CT) reveals a hyperdense media sign on the left (a,b, asterisk). Angiography confirmed M1 occlusion (c, arrow). Using the road map function the guidewire was positioned distal of the occlusion and the aspiration catheter could be placed right at the beginning of the occlusion (d, arrow). First pass, thrombolysis in cerebral infarction (TICl) 3 result (e, $\mathrm{TICl}$ grading system)

and categorised according to the KSCA concept. In the extra-occupational phase, mentoring should take place by suitable focused specialists of the department and access to a local coordinator should be ensured. The spectrum of patients and examinations should cover the entire area of specialisation. Ideally, the entire extraoccupational specialty training is carried out by just one radiological clinic and managed by a local program director, who finally signs the logbook and ensures a balanced distribution of work and training time.
The number of lecturers should be adapted to the needs of the learners and at least one of them should already have passed the specialty exam that candidates are aiming for. Furthermore, the lecturers should be active in university teaching, have had appropriate didactic training and should take part in the implementation of examinations. The equipment must be appropriate and radiation protection must be observed in accordance with national law. The required teaching materials should be accessible and, in addition to text books, also include access to e-learning and online journals. Participation in courses and academic work should be encouraged and documented. The learners should regularly be formally evaluated with regard to the competencies they have achieved, and progress should be discussed in the logbook as well as perceived opinions on the teaching environment and lecturers. The teaching hospitals for in-service specialist training should be accredited in accordance with applicable national law, depending on their location. The learners should pass a final examination which objectively 

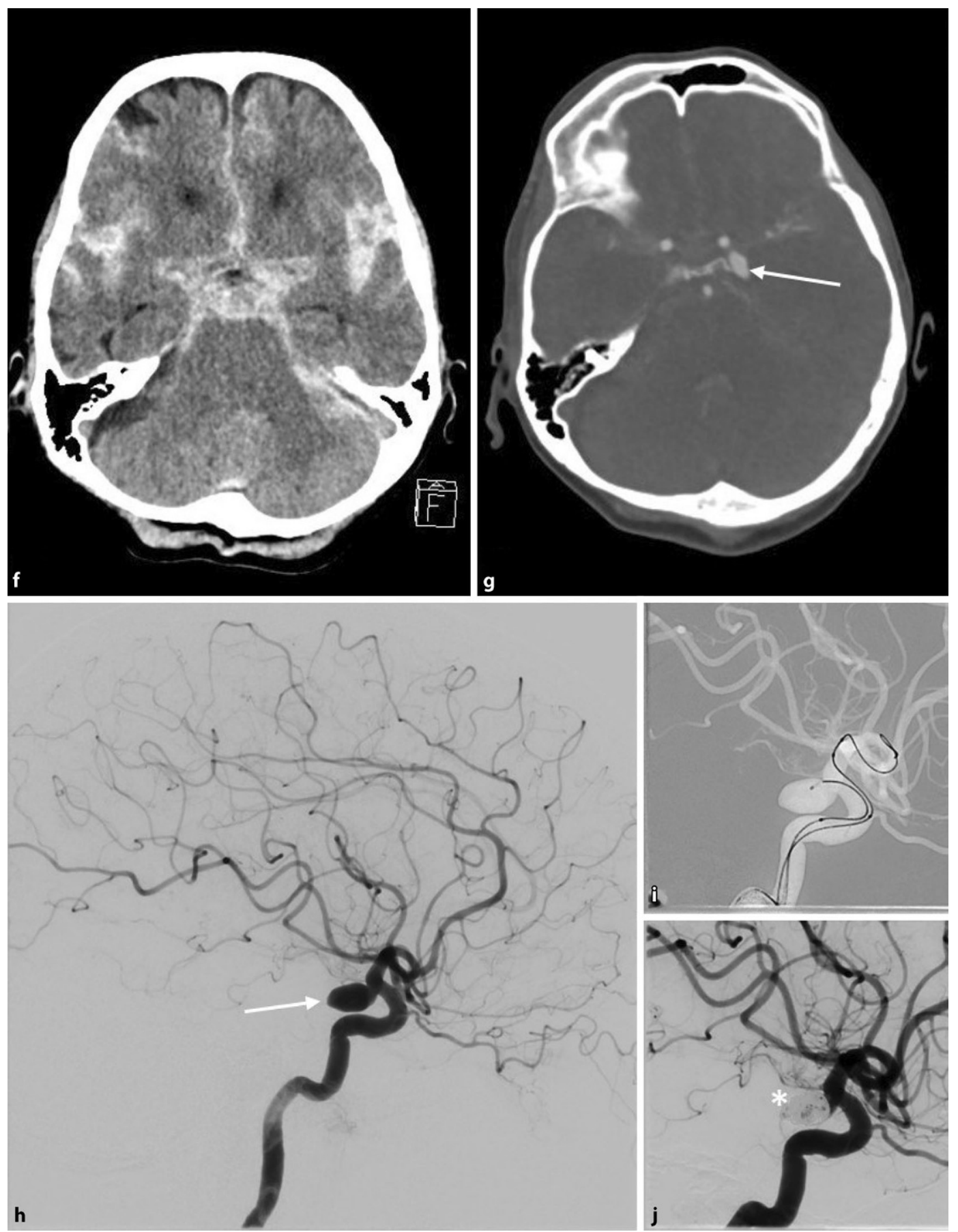

Fig. 34 (continued) Case 2 (female, 64 years): unenhanced $\mathrm{CT}$ shows severe subarachnoid haemorrhage (f), suspicious for a ruptured aneurysm which was confirmed to be a PCOM-type on CT angiography (g, arrow). Angiography confirmed the PCOM aneurysm ( $h$, arrow). Under protection, a microcatheter was placed in the neck of the aneurysm (i) and the aneurysm was very carefully filled with coils. Final control revealed a successful result (j, asterisk)

measures whether they are able to work independently in the corresponding focus subject [14, p. $9 \mathrm{ff}$.].

The KSCA concept began in 1956 with Bloom's taxonomy of cognitive learning goals and, for the first time, clearly formulated learning goals as measurable learning outcomes instead of learning content [16]. The KSCA concept makes it possible to determine preferable ways a learning objective should be mastered by the learner, which clearly has an impact on the proper teaching and evaluation methods to be used.

According to ETC Level III, "knowledge" (K) describes the classic list of learning topics. The term "skills" (S) describes psychomotor learning goals, which means all manually executable actions, technical skills and the application of knowledge. The term "competencies and attitudes" (CA) describes the affective learning goals on the one hand, and the consequence of repeated application of knowledge and skills on the other hand that lead to a deeper understanding and enable independent and responsible implementation [14, p. 13]. Such a grouping is abbreviated as KSCA. In ETC Level III, specific learning objectives are given for 13 different radiological subspecialties, which were formulated by the respective specialist societies according to the 

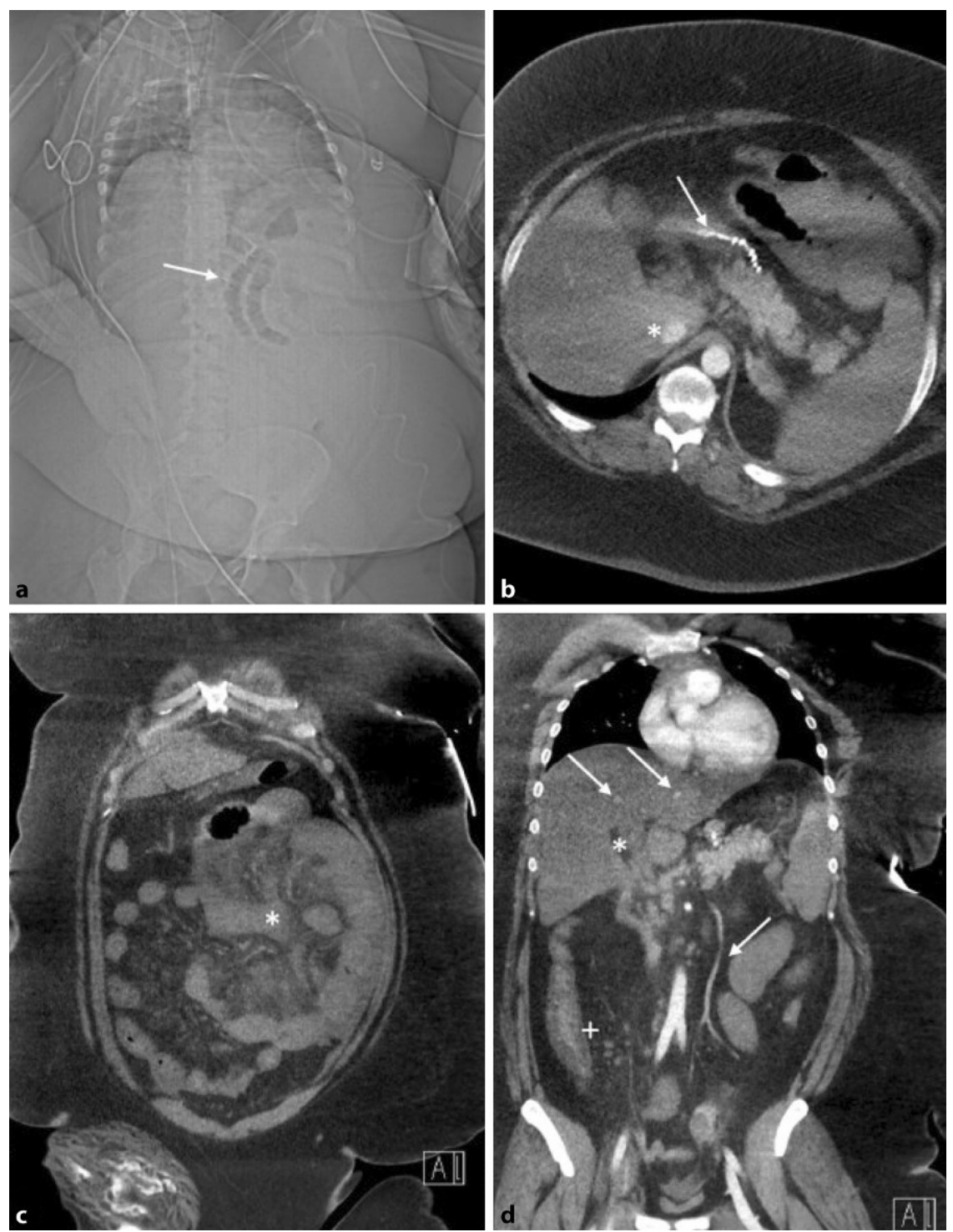

Fig. $4 \Delta$ Complete thrombosis of the portal vein. Obese patient after sleeve gastrectomy, 1 week after hospital discharge (female, 29 years). a Computed tomography (CT) scout, obese patient; note distribution of intraluminal bowel gas (arrow). b-d Enhanced CT in portal venous phase, limited image quality. Stapler seam of sleeve gastrectomy (b, arrow); note contrast in the inferior caval vein (b, asterisk). Swelling of small bowel, free fluid surrounding corresponding mesentery (c, asterisk) and iatrogenic active inguinal bleeding, right side. Acceptable venous contrast (d, arrows) except for the portal vein (d, asterisk). Note additional swelling of the ascending colon ( $\mathbf{d}$, cross). CT in arterial phase revealed no stenosis (not shown). The patient directly went to the operating room, and the inguinal bleeding was stopped quickly followed by open laparoscopy. Most of the small bowel was necrotic and eventually the patient had a fatal outcome

specifications of the ESR. The ER learning objectives of ETC Level III from 2015 [18] were revised and expanded during the curriculum development, categorised according to KSCA and anatomical aspects and published in the 2018 revised version $[14$, p. $35 \mathrm{ff}$.$] .$ to achieve this and in particular to solve the problem of the lack of specialisation in ER in Europe, the ESER board was motivated to develop a curriculum for the European Diploma in Emergency Radiology (EDER) [19]: "Although certain competencies in Emergency Radiology (ER) are shared by radiologists in Europe, educational contents and duration of training differ widely and no distinguished certificate is available so far. ESER aims to unify and offer the acquisition of ER competencies and certificates. Consequently, a curriculum for the EDER was developed as concrete implementation of the European Training Curriculum (ETC) Level III for ER" [19]. The EDER is endorsed by the ESR and aims to establish a common European qualification for radiologists in ER as a subspecialisation following general radiology training. It is organised centrally, but with the exception of congress visits and examinations, it can be acquired locally. The EDER consists of 11 learning sections, each (- Table 1) with associated webinars, workshops and self-directed learning. In addition, there is some scientific education as well as a 1-year speciality training at a teaching hospital in the home country of the participants. The final exam includes a written exam with multiple choice questions and a structured oral exam. Participation also requires proof of working for at least 5 years as a radiologist, 50 subject-specific CME points and active ESER membership (• Table 2).

\section{Emergency radiology in other European countries (examples)}

As it is impossible to describe all varieties, Italy and Spain were chosen to describe approaches which are different to the current procedure in Germany.

In Italy [20], training for clinical radiology takes 4 years. It involves training in general radiology, covering each radiology subspecialty, including ER. Rotation in ER lasts 4 months, during which residents have to collaborate in the implementation and reporting of at least 500 exams performed in this section. As an individual choice, residents have the option to spend 6-12 months in national or international centres with special expertise in certain areas. The European Diploma in Radiology (EDiR) is advised but not compulsory. 
Table 1 Sections (knowledge) of the European Diploma in Radiology (EDER, [19])

1 Head and brain

2 Spine, spinal cord and peripheral nerves

3 Fractures

4 Heart and big vessels

5 Intervention and angiography

6 Chest (non-traumatic, including interventions)

$7 \quad$ Abdomen (non-traumatic, including interventions)

8 Musculoskeletal system

9 Polytrauma

10 Special patient groups (children, pregnant women, geriatric and oncological patients)

11 Various (such as drugs, quality assurance, legal principles, radiation protection, organisational aspects, communication, team behaviour, decisions between life and death)

aThe 11 monthly orientated learning units are designed to enable completion within in 1 year (summer break in August). Since the curriculum runs for 2 years, every candidate has the opportunity either to repeat or to catch up on missed learning content

In Spain [21], training for clinical radiology also takes 4 years. It involves training in general radiology, covering each radiology subspecialty, including ER (3 months). In the final year, there is an elective period ranging from 3 months to 1 year for special interest training. This is available both domestically and internationally. The EDiR is also advised but is not compulsory.

\section{Emergency radiology in North America}

The ASER offers a training program similar to that of the ESER. This includes: webinars, online learning on demand, a core curriculum for specialisation in ER and own ER fellowships for the building of ER competence in the clinical environment [22].

In North America, there was early recognition of the importance of ER, with many institutions now having 24/7 dedicated divisions staffed by specifically trained Emergency Radiologists. "The emergency radiology facility has become the hospital's acute diagnostic imaging centre. The emergency radiology division of today is unique in its physical design, equipment, staffing, information systems, and oper- ations." ... "Future trends in emergency radiology will include response to an aging population; health care reform; new imaging modalities, such as cardiac CT; the need for radiation dose reduction; and increasing demand for MRI" [23].

The ASER was founded in 1988 and was the first society dedicated to ER. While it is a society in the USA, membership is open to international radiologists and trainees, constituting approximately $10-15 \%$ of its members, including members in training. Similar to the ESER, the ASER provides multiple avenues for learning, including: a 4-day annual meeting, which has been held for over 30 years [24], webinars, online learning on demand, a core curriculum for the specialisation in ER for both the resident and, separately, fellow level and a soon to be opened online ASER Academy.

In the US, there are approximately 30 fellowship positions at different institutions for a fellowship duration of 1 year. The fellowship directors are part of the ASER fellowship committee, which together with the ASER Executive Committee provides guidance to the independent programs on the interview process and curriculum.

In Canada, a fellowship program was started in 2003 (Vancouver General Hospital), which has since become the largest single-site 1-year fellowship program with up to 10 clinical fellows per year [25]. This was followed by programs in Ottawa and later by two separate trauma centres in Toronto, now with in total 16 fellowship positions available every year. This increased focus on ER, also with rotations in the residency programs, has led to the foundation of the Canadian Emergency, Trauma and Acute Care Radiology Society (CETARS), an affiliate society of the Canadian Association of Radiologists [26, 27]. Similar to the ASER and ESER, this society also provides dedicated education opportunities and guidelines.

In North America (both the USA and Canada), "there are basically three essential steps to becoming a radiologist: earning an undergraduate degree, earning a medical degree, and completing a radiology residency. The majority of radiologists also complete an additional year of highly specialised training called a fellowship" [28]. The radiology residency program comprises 1 year of internship in a surgical or internal medicine discipline, followed by 4 years of dedicated radiology rotations. As indicated above, with altogether 46 fellowship positions available, the ER fellowship is well established and its numbers are still growing. Many job opportunities exist to become a subspecialised radiologist performing only ER.

The classification of ER as its own specific subspecialty after many years of close collaboration of the ASER with the American Board of Radiology (ABR) in 2020 led to the first instance of ER being available as a dedicated subspecialty profile for continued board certification by specific inclusion in the Online Longitudinal Assessment (OLA), underscoring its maturity and further solidifying it as a proper subspecialty [29].

\section{Conclusions}

It remains somewhat imprecise at first glance what emergency radiology actually is. Is it, for example, acute radiology for potentially acutely life-threatening conditions such as serious injury, pulmonary embolism, heart attacks, strokes or other bleeding or vascular occlusions that can be treated interventionally? With or without children? With or without brain/neuro? Or is it 'just' the radiological care of patients in the emergency room?

Considering the EU framework, the position of the ESER is recommended. This defines ER as the radiological care of acute emergencies by radiologists who have the appropriate diagnostic and interventional competences. In addition, it refers to patients whose clinical picture requires an immediate diagnosis $24 / 7$ and, if necessary, acute therapy. Standard paediatric and neurological emergencies are included diagnostically but without interventional therapy, which is left to specialised paediatric radiologists and neuroradiologists.

The current German blueprint for medical specialist training regulations (WBO) defines a competence for "radiology in an emergency situation", but does not assign any reference numbers of key examinations to be performed. ER refers to acutely life-threatening conditions. Since, 


\begin{tabular}{|l|l|}
\hline Table 2 Key requirements for the European Diploma in Radiology (EDER, [19]) \\
\hline $\begin{array}{l}\text { Training in } \\
\text { Radiology }\end{array}$ & $\begin{array}{l}\text { Applicants have to prove at least } 5 \text { years of national training in radiology. A certificate of completed training needs to be provided. } \\
\text { For candidates with less than } 5 \text { years of national training, proof of experience as a supervised staff radiologist is required }\end{array}$ \\
\hline $\begin{array}{l}\text { Subspecialty } \\
\text { training }\end{array}$ & $\begin{array}{l}\text { At least } 2 \text { years of subspecialty training in ER (including an ER fellowship) or } 2 \text { years of work in an ER environment/facility, follow- } \\
\text { ing radiology certification, is required. A signed letter from the head of department/programme director has to be provided }\end{array}$ \\
\hline $\begin{array}{l}\text { RIS documen- } \\
\text { tation/logbook }\end{array}$ & $\begin{array}{l}\text { A total record of the candidate's experience in ER countersigned by the candidate's programme director is required (at least } 2 \text { years } \\
\text { of subspecialty clinical practice/training) }\end{array}$ \\
\hline $\begin{array}{l}\text { Webinars and } \\
\text { workshops }\end{array}$ & $\begin{array}{l}11 \text { ESER webinars. ESER recommends attending additional webinars and workshops to gain continuous education and training for } \\
\text { the diploma }\end{array}$ \\
\hline $\begin{array}{l}\text { Written exami- } \\
\text { nation }\end{array}$ & $\begin{array}{l}\text { The written part of the examination is based on multiple choice questions. Candidates' knowledge is tested in all aspects relevant } \\
\text { to ER such as anatomy, physiology, clinical practice, pathology, protocols and quality parameters }\end{array}$ \\
\hline $\begin{array}{l}\text { Oral examina- } \\
\text { tion }\end{array}$ & $\begin{array}{l}\text { The oral examination consists of a 20-min oral examination by ESER representatives in the English language. The examiners show } \\
\text { each candidate a series of cases. The examiners test all aspects of the cases relevant to ER: indication, clinical background, diagno- } \\
\text { sis, technical parameters, limitations, teamwork, therapeutic options, ethical aspects, etc. }\end{array}$ \\
\hline ER Emergency Radiology, RIS radiology information system, ESER European Society of Radiology \\
\hline
\end{tabular}

for example, strokes are included not only as a diagnostic skill but also as interventional therapy, such competence as part of general specialist training is likely to have only been acquired in exceptional cases. In addition, the specialist training period may formally be completed on a purely outpatient basis, and training experience outside normal working hours is not a prerequisite for admission to the examination as a board-certified specialist in Radiology. Whether aspects of ER are assessed within the board examination is also not prescribed (although it is certainly quite likely).

The DRG does not offer an own ER working group. Given the importance of ER within radiology, such a working group would be well suited to developing recommendations for the concrete improvement of ER training. It seems sensible to at least orientate oneself to the European framework and to use the corresponding preparatory work, such as that of the ESER or the offered EDER. A fellowship concept through specialised institutions, such as those offered by the ESER or ASER, appears helpful and could also improve ER training in Germany. Such an ER working group may first clarify the key aspects: What is the concept for ER training to be included during training in general radiology? Is there a need for a separate focus specialisation beyond the general training period?

In both cases, implementation of an ER curriculum should include modern concepts of medical didactics and teaching research, especially with regard to online concepts, activation of learners (and teach- ers), feedback as well as the methods for building practical skills and strengthening positive attitudes. Although different countries and societies place differing emphasis on ER, many of them like the ESR, the ESER, and the ASER provide useful concepts or possible partial concepts for adoption/adaption to a nonetheless individual German approach.

\section{Practical Conclusion}

- Training in ER differs widely across Europe and the world.

- Some countries offer particular ER specialisation or promote dedicated ER fellowships, while the ESER offers an ER diploma for specialisation/certification (EDER).

- In Germany, ER is part of the general training in radiology without a particular ER curriculum.

- The DRG may discuss introducing a separate working group for ER in order to develop a proposal for such a curriculum.

- A German ER working group may consider parts of international work in the field that have already been carried out, in particular by the ESR, the ESER and the ASER.

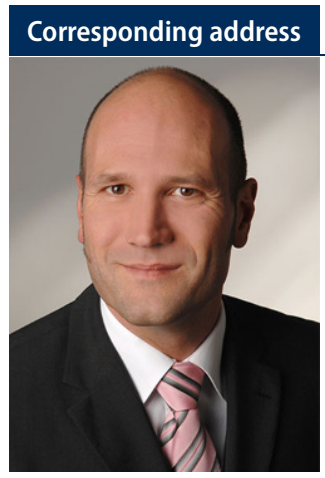

Prof. Dr. Dr. med. Stefan Wirth

Institut für Radiologie und Nuklearmedizin, Schwarzwald-Baar-Klinikum

Klinikstr. 11, 78052 Villingen Schwenningen, Germany

wirth.online@googlemail.com

\section{Declarations}

Conflict of interest. S. Wirth, F.H. Berger, A. Blanco Barrio, M.G. Wagner and R. Basilico declare that they have no competing interests.

For this article no studies with human participants or animals were performed by any of the authors. All studies performed were in accordance with the ethical standards indicated in each case.

The supplement containing this article is not sponsored by industry.

\section{References}

1. Harris jr JH (2001) Reflections: emergency radiology. Radiology 218:309-316

2. Brady AP, Bello JA, Derchi LE et al (2021) Radiology in the era of value-based healthcare: $A$ multisociety expert statement from the ACR, CAR, ESR, IS3R, RANZCR, and RSNA. Radiology 298:486-491

3. Pines JM, Hilton JA, Weber EJ, Alkemade AJ, Al ShabanahH, Anderson PDetal(2011) International 
perspectives on emergency department crowding. Acad Emerg Med 18:1358-1370

4. Morley C, Unwin M, Peterson GM, Stankovich J, Kinsman L (2018) Emergency department crowding: A systematic review of causes, consequences and solutions. PLoS ONE 13:e203316. https://doi. org/10.1371/journal.pone.0203316

5. Bundesärztekammer (Muster-)Weiterbildungsordnung 2018 - verabschiedet am 15.11.2018, zuletzt aktualisiert am 26.06.2021. https:// www.bundesaerztekammer.de/fileadmin/user_ upload/downloads/pdf-Ordner/Weiterbildung/ 20210630_MWBO_2018.pdf. Accessed 29 July 2021

6. Wagner MG (2019). Entwicklung eines Curriculums für die Schwerpunktspezialisierung in Notfallradiologie auf europäischer Ebene. Dissertation zum Doktor der Humanmedizin, Medizinische Fakultät der Ludwig-Maximilians-Universität, München, Deutschland

7. Wagner MG, Fischer MR, Scaglione M, Linsenmaier U, Schueller G, Berger FH et al (2017) Subspecialisation in emergency radiology: proposal for a harmonised European curriculum. GMS JMed Educ 34:Doc61

8. European Commission User guide for Directive 2005/36/EC on recognition of professional qualifications. https://ec.europa.eu/docsroom/ documents/40185/attachments/1/translations/ en/renditions/pdf. Accessed 14Nov 2021

9. Deutsche Röntgengesellschaft Arbeitsgemeinschaften in der DRG. https://www.drg.de/deDE/14/arbeitsgemeinschaften/. Accessed 28 July 2021

10. Braunschweig R, Janka R, Regier M (2020) Curriculum für die Facharztausbildung und die Weiterbildung in der Muskuloskelettalen Radiologie. Fortschr Röntgenstr 192:408-417

11. Braunschweig R, Reske S Protokollempfehlungen der AG Bildgebende Verfahren des Bewegungsapparats (AG BVB) zur Ganzkörper-CT mehrfach verletzter bzw. polytraumatisierter Patienten. https://www.ag-msk.drg.de/media/document/ 15091/protokollempfehlungen-gkct-ag-msk. pdf. Accessed 28 July 2021

12. AG Muskuloskelettale Radiologie AG Muskuloskelettale Radiologie in der deutschen Röntgengesellschaft. https://www.ag-msk.drg.de/deDE/5811/startseite/. Accessed 28 July 2021

13. Deutsche Röntgengesellschaft Curriculum Radiologie für das Studium der Humanmedizin in Deutschland. https://www.drg.de/ media/document/8127/Radiologie-CurriculumMedizinstudium-DRG.pdf. Accessed 4 Aug 2021

14. European Society of Radiology European training curriculum for subspecialisation in radiology. https://www.myesr.org/media/2840. Accessed 8 Aug 2021

15. Frank JR, Snell L, Sherbino J CanMEDS 2015 physician competency framework. Royal College of Physicians and Surgeons of Canada. http://www.royalcollege.ca/rcsite/documents/ canmeds/canmeds-full-framework-e.pdf. Accessed 9 Aug 2021

16. Bloom BS (1956) Taxonomy of educational objectives, 1stedn. Longmans, London, p 207

17. European Society of Radiology European training curriculum for subspecialisation in radiology. https://www.eser-society.org/app/uploads/ESREuropean-Training-Curriculum-Level-III.pdf. Accessed 5 Aug 2021

18. European Society of Emergency Radiology Statutes of the European Society of Emergency Radiology. https://www.eser-society.org/app/

\section{Notfallradiologische Weiterbildung in Deutschland - aktuelle Situation und zukünftige Ausrichtung}

Hintergrund: Die Notfallradiologie („emergency radiology“ [ER]) ist ein wichtiger Teil der Radiologie. Aber was genau ist Notfallradiologie? Wie können benötigte Kompetenzen gut und machbar erworben werden? Wer soll sich darum kümmern? Ziel der Arbeit: Diskussion der Inhalte von ER und Vorschläge zur Verbesserung des Erwerbs entsprechender Kompetenzen in der radiologischen Weiterbildung. Material und Methoden: Allgemeine Literaturaufarbeitung, insbesondere der aktuellen deutschen ärztlichen (Muster-)Weiterbildungsordnung (WBO 2020) sowie von Publikationen der Deutschen Röntgengesellschaft (DRG), der Europäischen Gesellschaft für Radiologie (ESR), der Europäischen Gesellschaft für Notfallradiologie (ESER) und der Amerikanischen Gesellschaft für Notfallradiologie (ASER).

Ergebnisse und Diskussion: In Deutschland ist als Nachweis für ER-Kompetenz im Rahmen der Facharztweiterbildung eine Bestätigung des Weiterbildungsermächtigten ausreichend, dass zur "Radiologie in der Notfallsituation ..., z. B. bei Polytrauma, Schlaganfall, Intensivpatienten“ eine "Handlungskompetenz" entweder "selbstverantwortlich" oder "unter Anleitung" besteht. Die ESER bezieht sich auf alle akuten Notfälle, deren Krankheitsbilder 24/7 einer sofortigen Diagnose und ggf. auch akuten Therapie bedürfen. ESER und ASER bieten unter anderem praktische Fellowships in spezialisierten Einrichtungen an; die ESER ergänzt dies mit einem europäischen Diplom in Notfallradiologie (EDER). Auf nationaler Ebene böte es sich an, vorhandene Definitionen, Angebote und Konzepte von ESR, ESER und ASER zu nutzen. Spezialisierte Einrichtungen könnten den ER-Kompetenzerwerb mit Fellowships unterstützen. Für Deutschland erscheint es sinnvoll, innerhalb der DRG eine eigene Arbeitsgemeinschaft Notfallradiologie zu gründen, die sich mit der entsprechenden Weiterentwicklung befassen soll.

\section{Schlüsselwörter}

Radiologie in der Akutsituation · Notfallsituation · Radiologische Weiterbildung · Europäisches Diplom in Notfallradiologie $\cdot$ Kompetenzen

uploads/ESER-Statutes-EN-2018-02-28.pdf. Accessed 2 Aug 2021

19. European Society of Emergency Radiology European diploma im emergency radiology. https://www.eser-society.org/eder/. Accessed 4 Aug 2021

20. RB1. http://www.miur.it "Ordinamenti didattici Scuole di Specializzazione di Area Sanitaria" http://www.miur.it/UserFiles/2198.S.\%20AREA \%20SANITARIA.pdf. Acessed 14 Nov 2021

21. Spanish Ministry of Health National Training Program in Clinical Radiology. Orden SCO/634/2008, de 15 de febrero, por la que se aprueba y publica el programa formativo de la especialidad de Radiodiagnóstico. «BOE» núm. 60, de 10 de marzo de 2008, páginas 14333 a 14341. https://www. boe.es/eli/es/o/2008/02/15/sco634 (Ref. BOE-A2008-4605). Acessed 14 Nov 2021

22. American Society of Emergency Radiology The American Society of Emergency Radiology, Homepage. https://aser.org/. Accessed 5 Aug 2021

23. Choy G, Novelline RA (2013) Past, present, and future of emergency radiology. Can Assoc Radiol J 64:85-89

24. American Society of Emergency Radiology Past meetings archive. https://aser.org/pastmeetings-archive/. Accessed 14 Nov 2021

25. University of Bristish Columbia Emergency \& trauma radiology, fellowship programs. https:// radiology.med.ubc.ca/education/fellowshipprograms/emergency-trauma-radiology/. Accessed 14 Nov 2021
26. Canadian Emergency, Trauma and Acute Care Radiology Society (CETARS) Homepage. https:// car.ca/cetars/. Accessed 14 Nov 2021

27. Canadian Association of Radiologists Homepage. https://car.ca/. Accessed 14 Nov 2021

28. Innerbody Research How to become a radiologist. https://www.innerbody.com/careers-in-health/ how-to-become-a-radiologist.html\#the-stepsto-become-a-radiologist. Accessed 5 Aug 2021

29. American Board of Radiology New year brings new features to OLA. https://www.theabr.org/blogs/ new-year-brings-new-features-to-ola. Accessed 14Nov 2021 